\title{
Studying the effects of strain heating on glacial flow within outlet glaciers from the Heimefrontfjella Range, Dronning Maud Land, Antarctica
}

\author{
Veijo A. POHJOLA, Jim HEDFORS \\ Department of Earth Sciences, Uppsala University, Villavägen 16, S-752 36 Uppsala, Sweden \\ E-mail: veijo.pohjola@geo.uu.se
}

\begin{abstract}
A one-dimensional numerical thermodynamic model is used to study the effects of strain heating on temperature profiles along the flowline of two outlet glaciers in Dronning Maud Land, Antarctica, flowing down a steep escarpment. Measurements of ice surface velocities on the glaciers show higher speeds than surface speeds calculated using Glen's flow law. These calculations are based on ice-temperature distributions excluding strain heating in the general heat equation. The incorporation of strain heating in the general heat equation produces higher ice temperatures, and calculated ice surface speeds that are close to the measured values. It is found that relatively short-scale temporal and spatial steps in basal topography are enough to drive the ice flow into a positive feedback loop as long as the bedrock step produces a stress that overcomes the advection of cool ice from the surface. In this case, where surface temperatures are $-25^{\circ} \mathrm{C}$, stresses of $0.4 \mathrm{MPa}$ are enough to drive the base of the ice to the melting point within $10^{2}$ years.
\end{abstract}

\section{INTRODUGTION}

Many ice masses are prone to large and rapid changes, such as glacier surges and the flow of ice streams. The processes and mechanisms leading to glacier surges or ice streams are many and various, but a governing premise in most theoretical models of fast glacial flow is the fact that the ratio between the gravity-related driving force of the ice mass and the resistive-friction force reaches some yield value. This sets the system into a positive feedback loop, whereby the driving-force/resistive-friction ratio increases step by step.

Many processes may cause fast glacial flow, including variations in subglacial hydraulics (Kamb, 1987; Humphrey and Raymond, 1994), deformation of subglacial sediments (Truffer and others, 2000; Kamb, 2001), and heat gain from sliding friction (Fowler and others, 2001) or from deformational heating in ice itself (Clarke and others, 1977; Echelmeyer and others, 1994; Payne, 1999). In this short review we do not distinguish between processes at work within ice streams and those within surging glaciers; in fact, some ice streams may be under continuous surge (Anandakrishnan and others, 2001).

This paper focuses on one of the processes that reduce friction: deformational heating, also known as strain heating. Strain heating is essentially a feedback loop that acts such that deformational work generates heat through dissipation. The viscosity of ice is a function of temperature, so when ice is heated, its viscosity decreases and it deforms faster. Increased deformation leads to faster ice flow, causing dissipation to increase further, and so on. This presents a positive feedback loop. This feedback loop demonstrates the potential inherent instability of ice masses, and has led to speculation about the rapid disintegration of ice masses (Yuen and others, 1986; Saari and others, 1987). Pioneering work in this field by
Clarke and others (1977) showed that the feedback loop operates on time-scales of $10^{2}-10^{3}$ years in valley glaciers (larger driving stresses, due to steeper slopes) and $10^{3}-10^{4}$ years in ice sheets (generally smaller driving stresses, due to gentler slopes). Clarke and others (1977) suggested that these growth times were too long to explain surging in valley glaciers but might have induced ice-sheet collapse in the mid-latitude ice sheets during the Late Pleistocene, triggered by a decrease in accumulation which slowed the advection of cooler surface ice into the ice sheet. However, later experiments showed that the instability is less dramatic and is probably confined to the margins; the interior of large ice sheets was found to have long reaction times to this instability process (Hindmarsh and others, 1989).

Another interesting aspect of the strain-heating feedback mechanism relates to the development of ice streams/fast glacial flow. Payne and Dongelmans (1997), in a numerical example, show how ice flow can organize itself into streaming/creeping patterns due to changes in viscosity, ultimately an effect of the strain-heating feedback. Initially small perturbations in ice temperature will be enough to drive the ice into strain-heating feedback loops. Small stochastic differences in driving stresses, geothermal heating or accumulation rates in an upstream portion of a catchment will produce a pattern of fast-flowing warm ice streams cutting through sluggish and cold ice further downstream. Using realistic boundary conditions, Verbitsky and Saltzman (1997) and Payne (1999) found that the organization of the Siple Coast ice streams by the Ross Sea, Antarctica, could be modeled when including strain heating in the thermodynamics of ice flow. This implies that strain-heating instability is an important process along a flowline, which is different from the investigations of potential of ice collapse by Yuen and others (1986), who studied the heating in a globally fixed position. 


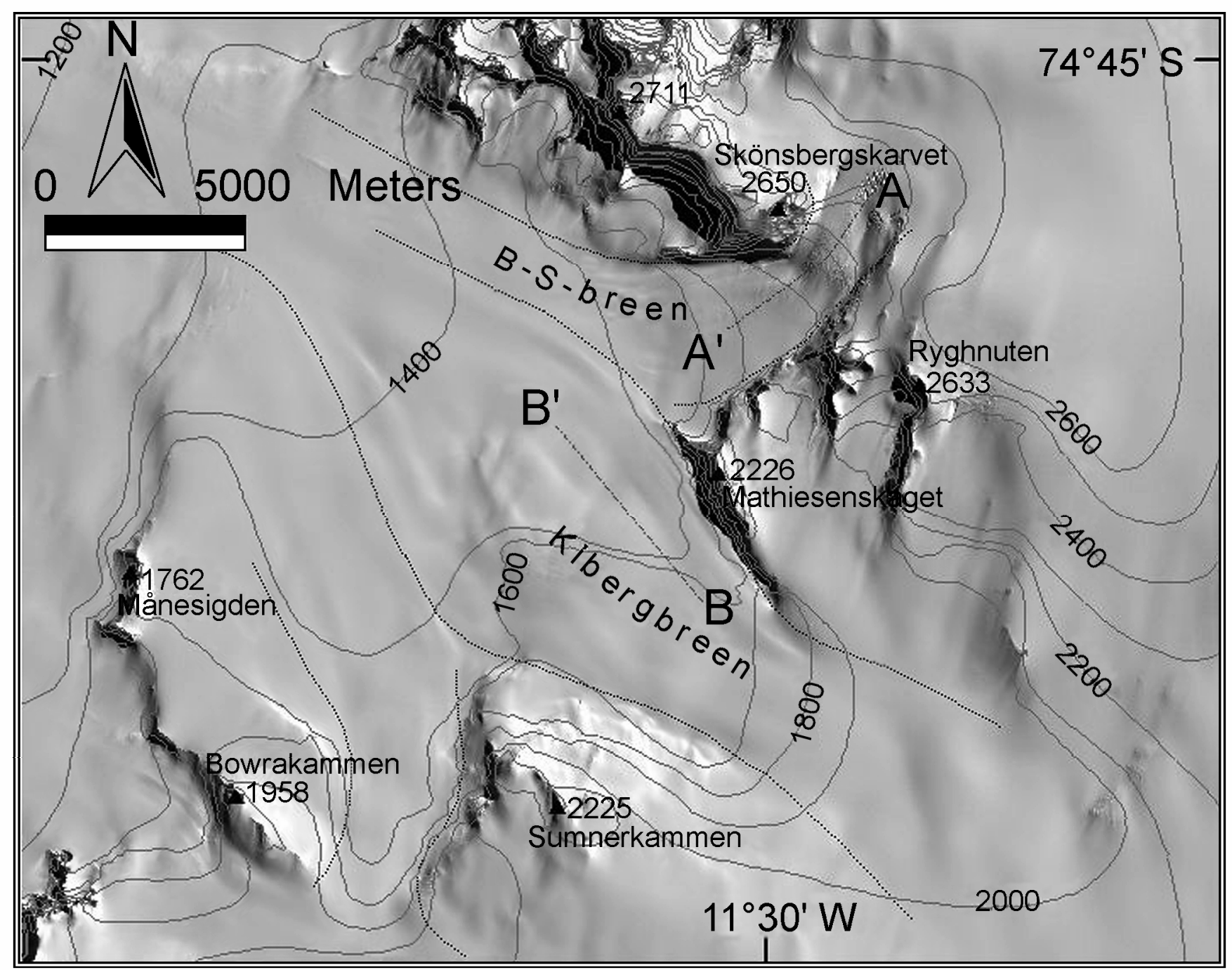

Fig. 1. The two glaciers in Heimefrontfjella, Dronning Maud Land, Antarctica: Bonnevie-Svendsenbreen (BSB) and Kibergbreen $(K B)$. The base of the map is a SPOT image, and the topographic information is from the Institut für Angewandte Geodäsie (Frankfurt, Germany) map Sivorgfjella (1:25000) and surface measurements (Pohjola and Stroeven, 1991). The dashed lines mark the boundary between the different ice flows in the area. The equidistance between contours is $100 \mathrm{~m}$.

This paper presents ice surface speed from two small outlet glaciers in Dronning Maud Land, Antarctica, and investigates whether the downhill increase in surface speed is related to, and perhaps even controlled by, a propagating decrease in ice viscosity due to strain heating of the ice column. We model temperature profiles of the ice column, and calculate the theoretical ice surface speed using Glen's flow law. The calculated ice surface speed is then compared to the measured values. By coupling or decoupling strain heating with the temperature model, we can estimate whether strain heating is a relevant process for the ice dynamics in these glaciers.

\section{DESGRIPTION OF THE ICE-TEMPERATURE MODEL}

The general equation for heat transfer is a partial differential equation, where heat is conducted and advected through the ice system between the atmospheric and the lithospheric boundaries in all three dimensions (Budd, 1969; Paterson, 1994),

$$
\begin{aligned}
\rho c \frac{\partial T}{\partial t} & =\nabla(K \nabla T) \\
& -\rho c\left(u \frac{\partial T}{\partial x}+v \frac{\partial T}{\partial y}\right)+\left(\frac{\mathrm{d} K}{\mathrm{~d} z}-\rho c w\right) \frac{\partial T}{\partial z}+Q,
\end{aligned}
$$

where $T$ is temperature, $t$ is time, $c$ is specific heat capacity,
$K$ is thermal conductivity, $\rho$ is ice density $\left(900 \mathrm{~kg} \mathrm{~m}^{-3}\right), u, v$, $w$ are the horizontal (along-flow), lateral (across-flow) and vertical ice velocities, and $Q$ is heat generated from internal and external heat sources. The parameters $c$ and $K$ are functions of temperature, and their empirical relations are given in Paterson (1994). The first term on the right side in Equation (1) is the conduction differential, and the three following terms are advection terms.

A component of internal heat is generated by internal friction, also called strain heating and dissipation. This friction is the resistance to flow exerted by the ice crystal lattices. This heat production is defined as being equal to the work done on the ice

$$
Q_{\mathrm{d}}=\dot{\varepsilon} \tau,
$$

where $Q_{\mathrm{d}}$ is the strain heat, $\dot{\varepsilon}$ is the strain rate and $\tau$ is the stress. Other heat sources contributing to $Q$ are processes at the boundary zones such as firn compaction, refreezing of meltwater and sliding friction at the base (Paterson, 1994). In the approach adopted here, the aim is to study how much a given ice column is heated primarily by strain heating, but also by conduction of geothermal heat, and how much time is required for a given driving stress to produce warm-based ice along a flowline. Therefore scenarios are sought in which 
strain heating is the dominant heat source. This can be done if the following assumptions are valid.

Firstly, energy released by basal sliding and basal freeze or consumed by basal melting is neglected. This is correct if energy production is calculated up to the point where basal temperatures just reach basal melting, and stops there. Further, a cold polar environment is considered with surface temperatures $<0^{\circ} \mathrm{C}$ so advection of meltwater is negligible. Heat from densification processes can also be regarded as negligible, if the lower-density layer (the firn/snow layer on top of the ice) is small with regard to the rest of the ice body, or, as in some of the cases accounted for later, if the lowdensity layer is non-existent due to wind erosion.

After canceling most of the heat sources from the boundary zones, we are left with geothermal heat, atmospheric heat and internal frictional heating. Heat from these sources is conducted diffusely and advected in all three dimensions as described in Equation (1).

To further simplify the problem, we now consider the advection terms. We assume the ice trajectories in our model are on the center line of an ice stream, so there is no lateral motion. The downslope horizontal flow cannot be neglected if we have an actively deforming body, but since we use a constant surface temperature for the area, the horizontal advection would have a small influence on the temperature profile. Also, the coordinate system will move downhill for each time-step such that it follows the flow of the surface ice. This is similar to a Lagrangian fashion of coordinates, and will, in principle, cancel horizontal advection since we follow the particles in the model.

Thus we use only the vertical advection term in our model. With the assumption that the vertical temperature gradient is larger than that in other directions (which implies that conduction is only important along the vertical axis), the heat equation becomes

$$
\rho c \frac{\partial T}{\partial t}=\left[K \frac{\partial^{2} T}{\partial z^{2}}+\left(\frac{\mathrm{d} K}{\mathrm{~d} z}-\rho c w\right) \frac{\partial T}{\partial z}+Q\right]
$$

(Paterson, 1994). The vertical advection, $w$, is assumed to decrease linearly with depth to a zero value at the bed.

The internal heat generation is proportional to stress and strain of the ice as shown in Equation (2). Using Glen's flow law for ice

$$
\dot{\varepsilon}=(\tau / B)^{n},
$$

where $n=3$, strain rate is substituted giving

$$
Q_{\mathrm{d}}=\tau^{4} B^{-3},
$$

and where

$$
\tau=\rho g h \sin \alpha .
$$

$\rho$ is ice density $\left(900 \mathrm{~kg} \mathrm{~m}^{-3}\right), g=9.82 \mathrm{~m} \mathrm{~s}^{-2}, h$ is ice depth, $\alpha$ is slope angle, and $B$ is the viscosity, dependent on temperature as

$$
B=B_{0} \exp \left(T_{0} / T\right),
$$

where $B_{0}=1.928 \mathrm{~Pa} \mathrm{a}^{1 / 3}, T_{0}=3155 \mathrm{~K}$. This relation is modified from Hooke (1981), who based his relation between ice viscosity and ice temperature on empirical data. The modification is made because temperatures close to melting give very soft and highly deformable ice in Hooke's version; about $25 \%$ softer than suggested by numerical modeling results of the deformation of temperate ice (Pohjola, 1993; Hanson, 1995). The modification of Hooke's version produces ice at high temperatures with greater viscosity, and is
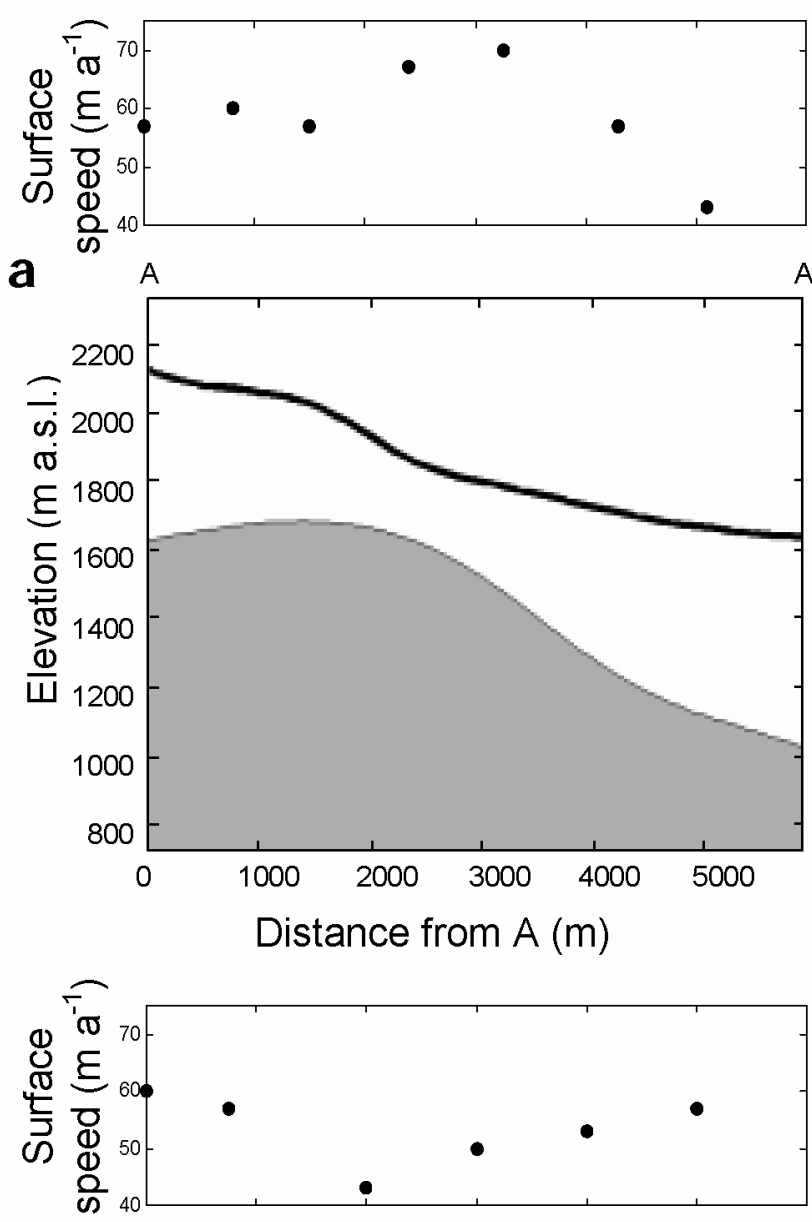

b

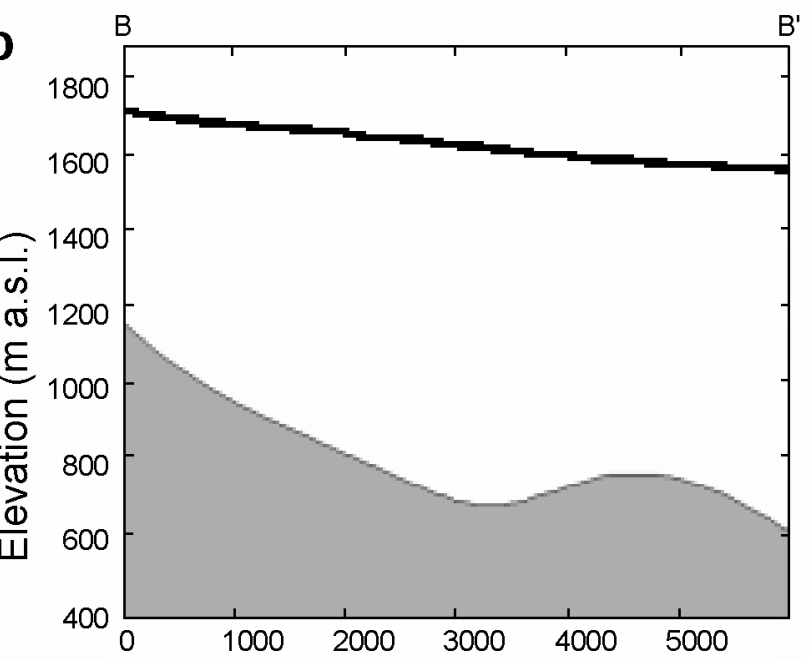

Distance from $B(m)$

Fig. 2. Longitudinal transects of $B S B(a)$ and $K B(b)$. The position of the transects is shown in Figure 1. The gray area is bedrock, and the thick gray line is the ice surface. Measured center-line ice surface speed is shown in a separate panel above each transect.

closer to the results from the numerical experiments. Equation (7) gives higher viscosity for a given temperature than Hooke's original concept, so calculations of strain heating will be conservative. This issue is discussed in more detail in the Discussion section below.

For the boundary condition with the atmosphere, a constant ice surface temperature is used. The geothermal heat flux for Paleozoic orogeny areas given by Budd (1969) is used as a constant for the lithosphere boundary, giving a relatively high geothermal input $\left(50 \mathrm{~mW} \mathrm{~m}^{-2}\right)$ and a temperature 
gradient at the lithosphere/cryosphere boundary of $0.02^{\circ} \mathrm{C} \mathrm{m}^{-1}$.

A time-marching Crank-Nicolson routine with a timestep of 1 year solves Equation (3). The temperature gradient at the lower boundary is fixed, the temperature at the surface is constant, and the calculated vertical temperature profile will change with time due to strain heating, conduction and vertical advection.

The horizontal ice speed $U(z)$ at depth is calculated using Equation (4) and the modeled vertical distribution of the ice temperature as

$$
U(z)=\int_{b}^{s}\left(\frac{f \tau_{z}}{B_{z}}\right)^{n} \mathrm{~d} z
$$

where $\tau_{z}$ and $B_{z}$ are the stress (Equation (6)) and the viscosity (Equation (7)), respectively, on each depth interval, and $f$ is the form factor, set to 0.5 which is equivalent to a semicircular channel feeling equal resistance along the rock-ice perimeter (Nye, 1965). We use this value of $f$ based on forcebudget analyses of Bonnevie-Svendsenbreen, Dronning Maud Land, indicating that stresses are evenly distributed along the perimeter (Pohjola and Hedfors, unpublished information), as within a semicircular cross-section. The reason for this is likely that the sides of the glacier are colder than the bed, and thus offer more resistance to flow.

In this experiment, we assume no basal slip (our calculated temperature profiles are valid up to the melting point of the basal ice). The suffixes $s$ and $b$ are the vertical position at surface $s$ and the base $b$ of the ice column, respectively.

\section{FIELD SITE AND MEASURED DATA}

The two outlet glaciers in the study are Bonnevie-Svendsenbreen (BSB) and Kibergbreen (KB) in Dronning Maud Land at $74^{\circ} 45^{\prime} \mathrm{S}, 11^{\circ} 30^{\prime} \mathrm{W}$ (Fig. 1). These two glaciers plunge down the escarpment Heimefrontfjella, separating the higher plateau Amundsenisen ( $3000 \mathrm{~m}$ a.s.l.) from a lower plateau Ritscherflya ( $1000 \mathrm{~m}$ a.s.l.) about $200 \mathrm{~km}$ inland from the southern Atlantic coast (Näslund, 1997).

Figure 2 shows the geometry and surface speed of each glacier along its center line. Surface speeds are derived from optical measurements in the field (Pohjola and Stroeven, 1991) and from tracking of surface features using satellite imagery (Système Probatoire pour l'Observation de la Terre (SPOT)). The ice speed is $43-70 \mathrm{ma}^{-1}$ on BSB, and $43-$ $60 \mathrm{~m} \mathrm{a}^{-1}$ on KB. The uncertainty is $<10 \%$ from the optical velocity surveys, and estimated to $<5 \%$ from the satellite analysis. The ice-depth data are from radio-echo surveys (Näslund and others, 2000). The average depths of these glaciers are $\sim 400 \mathrm{~m}(\mathrm{BSB})$ and $\sim 1000 \mathrm{~m}(\mathrm{~KB})$. The average slopes are $6.4^{\circ}(\mathrm{BSB})$ and $2.5^{\circ}(\mathrm{KB})$. The slopes and the depths are averaged over approximately $8.5 \mathrm{~km}$ (BSB; 1600$2600 \mathrm{~m}$ a.s.l.) and $13.5 \mathrm{~km}$ (KB; $1600-2000 \mathrm{~m}$ a.s.l.) (Fig. 1). The annual average ice surface temperature is estimated to be $-25^{\circ} \mathrm{C}$ based on $15 \mathrm{~m}$ temperatures measured in boreholes on BSB and KB (measured at 1600 m a.s.l.) (Näslund and others, 1991). The estimated accumulation rate in this area is about $0.25 \mathrm{~m} \mathrm{a}^{-1}$ ice equivalent (Isaksson and Karlén, 1994; Richardson and others, 1997). Both annual average surface temperature and accumulation rate are assumed to be similar on both glaciers.

\section{RESULTS}

\section{Comparing measured and calculated ice speeds without strain heating}

In order to compare the measured surface speeds, $U_{\mathrm{s}, \mathrm{m}}$ with calculated surface speeds, $U_{\mathrm{s}, \mathrm{c}}$ using Equation (8) we need a vertical temperature profile $T(z)$ with which to obtain the viscosity distribution in the ice $(B(z))$. The first issue is to calculate the steady-state profile of $T(z)$ for both glaciers, where $Q$ (the strain heating) is set to zero in Equation (3) (since we want to examine how important $Q$ is to $T(z)$ ). For these runs the vertical advection, $w_{\mathrm{s}}$, is assumed to be $0.25 \mathrm{~m} \mathrm{a}^{-1}$ ice equivalent, and $T_{\mathrm{s}}=-25^{\circ} \mathrm{C}$. $H$ was set to the average depths 400 (1000) $\mathrm{m}$ for BSB (KB). After 7200 (20000) years the iteration converged and steady-state profiles of $T(z)$ were achieved on BSB $(\mathrm{KB})$, and are shown in Figures $3 \mathrm{a}$ and $4 \mathrm{a}$ (noted as $\mathrm{S}-\mathrm{S}$ ). The basal temperature, $T_{\mathrm{b}}$, for the steady-state solution is $-19.5(-15.4)^{\circ} \mathrm{C}$ for BSB (KB). These calculated steady-state profiles are assumed to be within an area where vertical advection is greater than horizontal advection, i.e. close to an ice divide. For BSB this would be in the upper right corner of Figure 1, and for KB this is some distance upstream of the boundary of Figure 1.

Having $T(z)$ for both glaciers, we can solve $B_{z}$ and obtain $U_{\mathrm{s}, \mathrm{c}}$ using Equation (8), where c is calculated and $\mathrm{m}$ is measured. Assuming the steady-state profiles of $T(z)$ are constant along the slopes of BSB and KB (Fig. 1), Figures 3b and $4 \mathrm{~b}$ show that $U_{\mathrm{s}, \mathrm{c}}$ is $10.9(36.8) \mathrm{m} \mathrm{a}^{-1}$ for BSB $(\mathrm{KB}) . U_{\mathrm{s}, \mathrm{m}}$ for the two glaciers is $43-70(43-60) \mathrm{m} \mathrm{a}^{-1}$ on BSB (KB) (Fig. 2), showing $U_{\mathrm{s}, \mathrm{c}}<U_{\mathrm{s}, \mathrm{m}}$ on both $\mathrm{BSB}$ and $\mathrm{KB}$. On $\mathrm{KB}$ the value of $U_{\mathrm{s}, \mathrm{c}}$ is $82 \%$ of the lowest value of $U_{\mathrm{s}, \mathrm{m}}$, while $U_{\mathrm{s}, \mathrm{c}}$ is only $61 \%$ of the highest value of $U_{\mathrm{s}, \mathrm{m}}$. The difference between $U_{\mathrm{s}, \mathrm{c}}$ and $U_{\mathrm{s}, \mathrm{m}}$ on $\mathrm{KB}$ may be due to uncertainties in determining the surface velocity from Equation (8) (e.g. the simplifications made concerning average surface slopes, ice depths and effects of longitudinal coupling). On BSB the highest value of $U_{\mathrm{s}, \mathrm{c}}$ is only $28 \%$ of $U_{\mathrm{s}, \mathrm{m}}$, and it seems improbable that uncertainties in the method, or smoothing of parameters, would result in such a difference. As an example we calculate $U_{\mathrm{s}, \mathrm{c}}$ for a specific point on BSB. We use the coordinate $5100 \mathrm{~m}$ in the $\mathrm{A}-\mathrm{A}^{\prime}$ profile in Figure 2a. $U_{\mathrm{s}, \mathrm{m}}$ at this point is $43 \pm 3 \mathrm{~m} \mathrm{a}^{-1}$, based on optical measurements over a 22 day interval (Pohjola and Stroeven, 1991). At this point the ice depth is $485 \mathrm{~m}$ and the surface slope averaged over a length of $1.2 \mathrm{~km}$ is $2.4^{\circ}$. Using the steady-state temperature profile $(Q=0)$, with basal ice temperature of $-19.5^{\circ} \mathrm{C}$, Equation (8) gives $U_{\mathrm{s}, \mathrm{c}}=1.3 \mathrm{~m} \mathrm{a}^{-1}$, which is only $3 \%$ of the measured velocity. This is a large difference and the assumptions and generalizations we have used cannot account for this discrepancy. Our conclusion is that $Q$, and specifically strain heating, must be important in Equation (3) in order to heat the basal ice to a lesser viscosity, and in such a way increase the deformation of the ice column.

\section{Comparing measured and calculated ice speeds using strain heating}

Clearly, the ice column must be warmer than the steadystate temperature profile suggests, in order to explain the relatively high ice speeds on $\mathrm{BSB}$. On $\mathrm{KB}$ the difference is less pronounced. In order to study whether strain heating can explain the discrepancy between $U_{\mathrm{s}, \mathrm{c}}$ and $U_{\mathrm{s}, \mathrm{m}}$ we let $Q$ vary in accordance with Equation (5) and calculate new temperature profiles using Equation (3). In these calcula- 

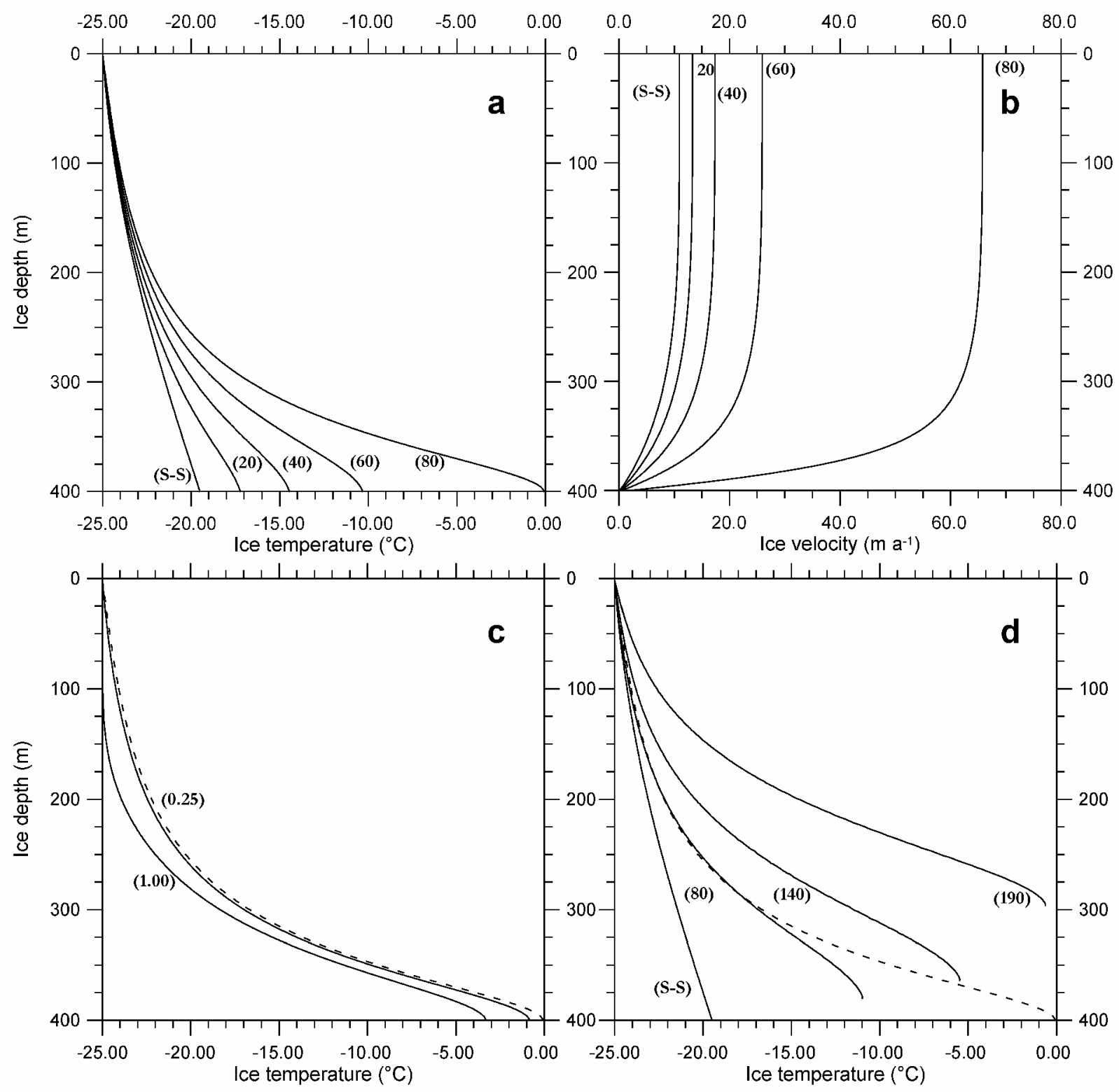

Fig. 3. The thermal ( $a$ ) and ice-speed ( $b$ ) evolution from the model using input data from BSB. The distributions shown are products of the steady-state thermal profile $(S-S)$ using no strain heating, and with strain heating of the steady-state profile after 20, 40,60 and 85 years. The model of constant geometry was used in these calculations, and vertical advection was assumed to be negligible in the strain-heat runs. (c) How vertical advection changes the thermal profile, using no vertical advection (dashed line), $0.25 \mathrm{~m}^{-1}$ and $1 \mathrm{~m} \mathrm{a}^{-1}$. (d) The thermal and ice-thickness evolution using a constant-flux model (conservation of mass). The distributions are shown as a product of the steady-state thermal profile $(S-S)$ using no strain heating, and with strain heating of the steady-state profile after 80, 140 and 190 years. The vertical advection was set to $0.25 \mathrm{~m} a^{-1}$ in these runs. The dashed distribution shows the 80 years of strain heat from $(a)$.

tions we assume that the ice column is moving along the flowlines. The flowlines follow the routes indicated by sections $\mathrm{A}-\mathrm{A}^{\prime}$ and $\mathrm{B}-\mathrm{B}^{\prime}$ in Figure 1 , but are extended in the upper and lower parts of the A and B sections (see Field site and measured data). So, both flowlines will begin above points $\mathrm{A}$ and $\mathrm{B}$, such that the BSB flowline starts at the ice divide in the upper right corner of Figure 1 and the KB flowline starts at the beginning of the steeper part of the slope upstream of Figure 1. The initial values of $T(z)$ are from the steady-state profiles from the previous subsection, and new temperature and speed profiles are calculated at each time-step as the ice moves along the flowlines. In a first approach, we assume that surface slope and ice depth is constant along the flowline (which implies that ice flux is increasing as ice velocity increases downstream). Figure $3 \mathrm{a}$ (4a) shows the evolution of $T(z)$ in $\mathrm{BSB}(\mathrm{KB})$ as the strain heating warms the ice column. Input data are given in Tables 1 and 2. Using the average slopes of $6.4(2.5)^{\circ}$ and ice depths of $400(1000) \mathrm{m}$ gives high forces to each glacier, and gives a driving stress of $0.4 \mathrm{MPa}$ for both glaciers. These stresses are very high compared with values normally found at most glaciers. Such a driving stress is capable of heating basal ice to the point of melting in 80 (36) years on BSB (KB) (Fig. 3a (4a); Table 1 (2)). We find that after 70 (20) years of strain heating we get $U_{\mathrm{s}, \mathrm{c}}$ comparable to $U_{\mathrm{s}, \mathrm{m}}$ on BSB (KB). This accounts for only $1.5(0.9) \mathrm{km}$ of movement along the flowline on BSB (KB) (Table 1 (2)).

In the strain-heat experiments, the vertical advection $w_{\mathrm{s}}$ was set to 0 when calculating the evolution of the thermal profile flowing along the flowline. Time zero is the steadystate profile at the start. The assumption of zero vertical advection is based on the fact that the steep glacier surfaces 
Table 1. Results from selected runs on geometry on BSB, as shown in Figure 3

\begin{tabular}{|c|c|c|c|c|c|c|}
\hline$w_{\mathrm{s}}$ & $t$ & $H_{\text {out }}$ & $T_{\mathrm{b}}$ & $T_{\mathrm{Av}}$ & $U_{\mathrm{s}}$ & $L$ \\
\hline $\mathrm{ma}^{-1}$ & years & $\mathrm{m}$ & ${ }^{\circ} \mathrm{C}$ & ${ }^{\circ} \mathrm{C}$ & $\mathrm{ma}^{-1}$ & $\mathrm{~km}$ \\
\hline 0 & 1 & 400 & -19.4 & -22.8 & 10.9 & 0.01 \\
\hline 0 & 20 & 400 & -17.2 & -22.3 & 13.3 & 0.24 \\
\hline 0 & 40 & 400 & -14.5 & -21.6 & 17.4 & 0.54 \\
\hline 0 & 60 & 400 & -10.3 & -20.8 & 25.9 & 0.96 \\
\hline 0 & 80 & 400 & -0.1 & -19.1 & 65.4 & 1.76 \\
\hline 0.25 & 80 & 400 & -0.8 & -19.4 & 61.0 & 1.72 \\
\hline 0.25 & 80 & 380 & -11.0 & -20.7 & 20.9 & 1.06 \\
\hline 0.25 & 195 & 167 & -0.1 & -16.7 & 2.8 & 3.07 \\
\hline 1.0 & 80 & 400 & -3.3 & -20.5 & 46.8 & 1.57 \\
\hline 1.0 & 160 & 351 & -1.0 & -19.4 & 41.6 & 2.76 \\
\hline
\end{tabular}

Notes: $\alpha_{\text {in }}$ is $6.4^{\circ}, H_{\text {in }}=400 \mathrm{~m}$, giving a $\tau_{\mathrm{d}}$ of $0.40 \mathrm{MPa} . w_{\mathrm{s}}$ is the vertical velocity at surface. $t$ is time used for each run. $H_{\text {out }}$ is the ice thickness at the end of the run. In the runs where $H_{\text {out }}=H_{\text {in }}$ (i.e. where $H_{\text {out }}=$ $400 \mathrm{~m}$ ), the criterion conservation of mass was not obeyed. $T_{\mathrm{b}}$ and $T_{\mathrm{Av}}$ are basal temperature and average temperature in the column. $U_{\mathrm{s}}$ is the horizontal surface velocity at $t$, calculated as in Equation (8). $L$ is the sum of surface velocity over all time-steps, giving the flowed length of the column along the flowline since start.

are swept by katabatic winds and do not gain much accumulation at their steeper parts (Richardson-Näslund, 2001). We find that $T(z)$ and $U_{\mathrm{s}, \mathrm{c}}$ do not change much by setting $w_{\mathrm{s}}=$ $0.25 \mathrm{~m} \mathrm{a}^{-1}$ (Fig. 3c (4c); Table 1 (2)), showing that strain heating is much more powerful than cooling by vertical advection, at least where annual accumulation rates are low. Figure 1 shows that both BSB and KB are fed by tributaries along the flowline. Earlier studies have shown that lateral boundaries are important regulators of fast glacier flow (Raymond and others, 2001) and lateral advection by the convergence of ice (Funk and others, 1994; Hindmarsh, 2001). By drawing lateral ice into the system, we may provide a mechanism by which to reverse the feedback and cool the ice. A simplistic way to simulate this effect is to increase $w_{\mathrm{s}}$ to some value much larger than the accumulation rate $\left(0.25 \mathrm{~m} \mathrm{a}^{-1}\right)$. We use $w_{\mathrm{s}}=1.0$ (5.0 and 10.0$) \mathrm{ma}^{-1}$ for BSB (KB). The effect of the increase in $w_{\mathrm{s}}$ is shown in Figure 3c (4c) and in Table 1 (2), showing that large amounts of cold inflowing ice are necessary in order to reverse the strainheating feedback loop. For KB $w_{\mathrm{s}}$ needs to be as high as $10 \mathrm{~m} \mathrm{a}^{-1}$ in order to reverse the loop into a negative feedback and cool the base of the glacier (Fig. 4c). We acknowledge that lateral conduction of heat between ice streams and vertical advection through snow accumulation differ in their mechanisms and heat distributions. At this particular site they are more similar, though, because several small icefalls drape the lateral boundaries of the ice streams. Episodic ice avalanches, and sub-vertical flows feed the ice streams (especially BSB) with cold ice to the surface of the ice streams, giving a likely input to the (at least local) energy balance.

In the strain-heating experiments, we have so far used a model that does not obey conservation of mass. The reason the geometry of the glacier is held constant despite increasing ice speed is that this model is a necessary simplification of the complex three-dimensional dynamics that operate in these glaciers. In the case of BSB the ice is horizontally compressed along the flowline $\mathrm{A}-\mathrm{A}^{\prime}$, as seen in Figure $2 \mathrm{a}$ as ice thickens and slows down downstream, when meeting the larger $\mathrm{KB}$ almost at a right angle to the flow of $\mathrm{KB}$, where $\mathrm{KB}$ with the larger momentum, deflects the weaker BSB.
Table 2. Results from selected runs on geometry on $K B$, as shown in Figure 4

\begin{tabular}{|c|c|c|c|c|c|c|}
\hline$w_{\mathrm{s}}$ & $t$ & $H_{\text {out }}$ & $T_{\mathrm{b}}$ & $T_{\mathrm{Av}}$ & $U_{\mathrm{s}}$ & $L$ \\
\hline $\mathrm{ma}^{-1}$ & year & $\mathrm{m}$ & ${ }^{\circ} \mathrm{C}$ & ${ }^{\circ} \mathrm{C}$ & $\mathrm{ma}^{-1}$ & $\mathrm{~km}$ \\
\hline 0 & 1 & 1000 & -15.2 & -22.1 & 36.8 & 0.04 \\
\hline 0 & 10 & 1000 & -13.2 & -21.8 & 42.7 & 0.40 \\
\hline 0 & 20 & 1000 & -10.3 & -21.4 & 53.1 & 0.88 \\
\hline 0 & 30 & 1000 & -5.8 & -20.8 & 74.6 & 1.51 \\
\hline 0 & 35 & 1000 & -1.9 & -20.5 & 98.9 & 1.95 \\
\hline 0.25 & 35 & 1000 & -2.0 & -20.6 & 98.3 & 1.94 \\
\hline 0.25 & 35 & 838 & -7.2 & -21.5 & 55.8 & 1.35 \\
\hline 0.25 & 55 & 644 & -1.2 & -20.3 & 19.7 & 2.19 \\
\hline 5 & 50 & 830 & -1.1 & -23.3 & 33.9 & 1.71 \\
\hline 10 & 35 & 1000 & -12.5 & -24.4 & 96.3 & 0.82 \\
\hline 10 & 200 & 1000 & -18.3 & -24.7 & 41.6 & 2.76 \\
\hline 10 & 35 & 1047 & -10.0 & -24.4 & 31.2 & 0.96 \\
\hline 10 & 85 & 905 & -0.6 & -24.0 & 33.5 & 2.78 \\
\hline
\end{tabular}

Notes: $\alpha_{\text {in }}$ is $2.5^{\circ}, H_{\text {in }}=1000 \mathrm{~m}$, giving a $\tau_{\mathrm{d}}$ of $0.39 \mathrm{MPa}$

The one-dimensional model used here is a simple tool, but sufficiently advanced to sense whether strain heating is or is not important in these ice flows. In order to study whether a conservation-of-mass condition has any substantial effects on the calculated temperature profiles, we undertook a set of runs in which the ice fluxes were set constant with time. In Figures $3 \mathrm{~d}$ and $4 \mathrm{~d}$ and in Table 3 we show the results from these runs.

The effect on the results of incorporating conservation of mass is a decreasing ice thickness downslope as the glacier slowly accelerates. Figures $3 d$ and $4 d$ also show that using the conservation-of-mass condition heats up the ice column to the melting point. The time for the heating to melting point was, however, delayed in each glacier, giving a factor of 2 times less heat production. If we increase the vertical advection $w_{\mathrm{s}}$, as we did in the earlier experiments, up to $1-5 \mathrm{~m} \mathrm{a}^{-1}$, we increase the heating again, since the larger influx of ice balances ice flux, and keeps ice thickness closer to a constant value.

\section{DISGUSSION AND GONGLUSIONS}

We have studied the effects of strain heating within two coldbased glaciers. We found it to be a significant heat source, at least on one of these glaciers, and it may explain the relatively high ice velocities measured on the surface of these glaciers. We have varied the input of vertical advection and tested whether a conservation-of-mass criterion will alter the output from the model. Varying the input between reasonable values does not rule out strain heating as an important mechanism for heating up the ice column in these glaciers.

In this work, we assumed that $Q$ in Equation (1) is equal to strain heating $\left(Q_{\mathrm{d}}\right)$ only. This generalization is valid as long as the melting point is not reached at the bed. When the melting point is reached, sliding friction between the bed and the ice will conduct heat up the ice column and increase melt rates at the bed. The latent heat needed to melt the ice is a negative feedback to this process.

For both glaciers, we used a form factor of 0.5 in Equation (8). This requires stresses to be equally distributed along the entire frozen perimeter. Increasing $f$ also increases the ice speed, without a necessary temperature increase. In Table 4 we show that $f$ needs to be of the order of 0.75 to allow 
Table 3. Results from runs on BSB and KB, using the conservation-of-mass criterion

\begin{tabular}{|c|c|c|c|c|c|c|c|}
\hline$w_{\mathrm{s}}$ & $t$ & $H_{\text {in }}$ & $H_{\text {out }}$ & $T_{\mathrm{b}}$ & $T_{\mathrm{Av}}$ & $U_{\mathrm{s}}$ & $L$ \\
\hline $\mathrm{ma}^{-1}$ & year & $\mathrm{m}$ & $\mathrm{m}$ & ${ }^{\circ} \mathrm{C}$ & ${ }^{\circ} \mathrm{C}$ & $\mathrm{ma}^{-1}$ & $\mathrm{~km}$ \\
\hline 0.25 & 80 & 400 & 380 & -11.0 & -20.7 & 20.9 & 1.06 \\
\hline 0.25 & 140 & 400 & 364 & -5.5 & -18.8 & 33.9 & 2.03 \\
\hline 0.25 & 190 & 400 & 296 & -0.6 & -16.9 & 26.2 & 2.99 \\
\hline 0.25 & 35 & 1000 & 838 & -7.2 & -21.5 & 33.8 & 1.13 \\
\hline 0.25 & 55 & 1000 & 644 & -1.2 & -20.3 & 19.7 & 2.19 \\
\hline 1.00 & 160 & 400 & 351 & -1.0 & -19.3 & 41.6 & 2.76 \\
\hline
\end{tabular}

observed ice speeds on BSB. If a parabolic cross-section is assumed, then the geometric values of BSB give $f=0.63$ (Nye, 1965). As described earlier, we believe that $f=0.5$ better describes the stress distribution on these glaciers.

The sensitivity of the calculated ice speed and ice temperature of BSB to geothermal flux is shown in Table 4. In order to heat the ice column sufficiently to equate calculated
Table 4. Test of the sensitivity of ice speed on BSB by changing the form factor, $f$, the viscosity, $B_{\text {test }}$ (as $\%$ of $B(z)$ ), the geothermal heat flux, $Q_{\mathrm{g}}$, and the surface temperature, $T_{\mathrm{s}}$

\begin{tabular}{rrrrrrr}
\hline$f$ & $B_{\text {test }}$ & $Q_{\mathrm{g}}$ & $T_{\mathrm{s}}$ & $T_{\mathrm{b}}$ & $T_{\mathrm{Av}}$ & $U_{\mathrm{s}}$ \\
& $\%$ & $\mathrm{~mW} \mathrm{~m}^{-2}$ & ${ }^{\circ} \mathrm{C}$ & ${ }^{\circ} \mathrm{C}$ & ${ }^{\circ} \mathrm{C}$ & $\mathrm{m} \mathrm{a}^{-1}$ \\
\hline 0.5 & 100 & 50 & -25 & -19.4 & -22.8 & 10.9 \\
0.5 & 75 & 50 & -25 & -19.4 & -22.8 & 11.1 \\
0.5 & 50 & 50 & -25 & -19.4 & -22.8 & 11.7 \\
0.5 & 25 & 50 & -25 & -19.4 & -22.8 & 20.3 \\
0.5 & 20 & 50 & -25 & -19.4 & -22.8 & 39.3 \\
0.63 & 100 & 50 & -25 & -19.4 & -22.8 & 21.3 \\
0.75 & 100 & 50 & -25 & -19.4 & -22.8 & 36.9 \\
0.5 & 100 & 50 & -30 & -24.4 & -27.7 & 5.2 \\
0.5 & 100 & 50 & -20 & -14.6 & -17.8 & 22.6 \\
0.5 & 100 & 100 & -25 & -16.6 & -20.6 & 20.4 \\
0.5 & 100 & 150 & -25 & -8.2 & -18.5 & 37.7 \\
& & & & & & \\
\hline
\end{tabular}

Notes: All runs are after 7200 years, similar to the steady-state run in Table 1 , with $w_{\mathrm{s}}=0.25 \mathrm{~m} \mathrm{a}^{-1}$, and $H$ is constant $(400 \mathrm{~m})$. In all these runs, strain heating is set idle. Other parameters as in Table 1 footnote.
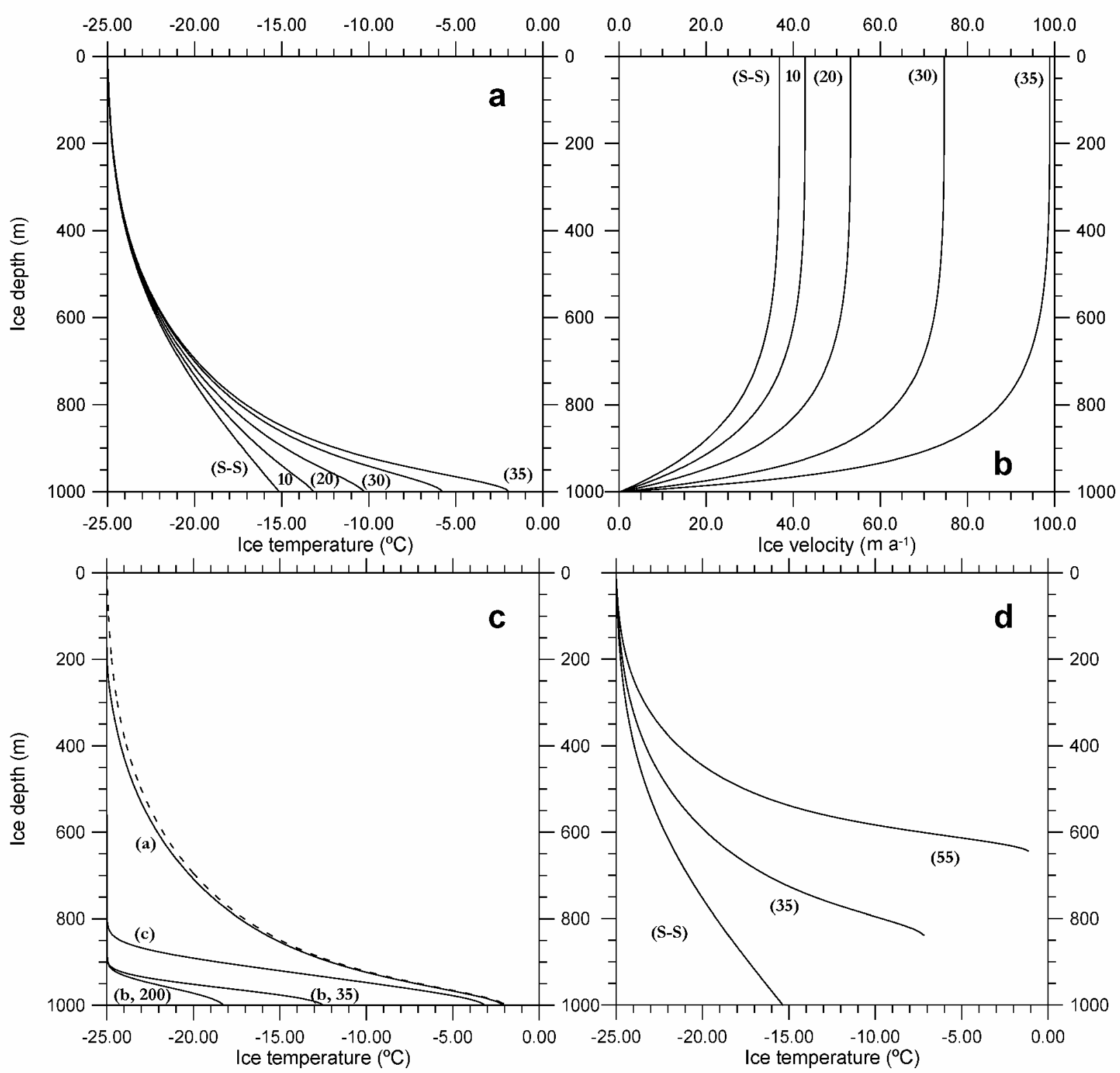

Fig. 4. Similar to Figure 3, but calculations for KB. Different from Figure 3 are the times shown in ( a) and (b):10, 20, 30 and 35 years. (c) How the vertical advection changes the thermal profile, using no vertical advection (dashed line), $0.25 \mathrm{ma}^{-1}$ (a), $5 \mathrm{ma} a^{-1}(\mathrm{c})$ and $10 \mathrm{~m} \mathrm{a}^{-1}(\mathrm{~b})$. (d) similar to Figure $3 d$, with evolution shown after 35 and 55 years. 
and measured speeds, without strain heat, we need to triple the geothermal heat flux. We regard this as an unlikely heat flux inside the craton of East Antarctica, where the regionally last tectonic activity is Permean in age.

We also test how large the changes in ice viscosity need to be in order to produce calculated ice speeds close to the measured speeds. In Table 4 we find that $B(z)$ needs to be reduced to $20 \%$ of the $B(z)$ used in the model in order for ice speeds to be high enough (without including strain heating in Equation (3)). Linked to this sensitivity test is the matter of Hooke's original formulation of $B$ and the altered version of his relation we use. Our simplified version of $B$ gives $12 \%$ harder ice than Hooke's formulation when $T=-1^{\circ} \mathrm{C}$. This difference decreases to $0.4 \%$ for $T=-20^{\circ} \mathrm{C}$. Running BSB without strain heating yields no difference in calculated ice speeds using Hooke's or our formulation of $B$, since ice is relatively cold. The formulation of $B$ therefore does not explain the difference between measured and calculated ice speed, disregarding strain heat.

The surface temperature we use in these runs is measured at $1600 \mathrm{~m}$ a.s.l. Using a conservative lapse rate on air temperatures gives about $5^{\circ} \mathrm{C}$ colder temperatures at 2600 ma.s.l., where BSB has its upper reach. The glaciers are affected by katabatic winds, and cold air is advected downslope of the glaciers. Using a conservative approach, we assume the air temperatures to be constant with height. In reality, the upper reaches likely are colder, which would slow our calculated ice speeds (Table 4).

A limitation of the model is the motion of the ice column downstream. The method of calculating the temperature column is similar to that in Robin's moving-column model (Robin, 1955). In the calculation of the ice-motion profiles from Equation (8) it is clear that ice motion is different at different ice depths. One effect of calculating the time evolution of the ice temperature using a column model instead of a proper ice-flow model is that basal ice would be progressively younger away from the ice divide, and would therefore have a limited heating history compared with that produced by a perfect model. The age and history of basal ice is a problematic issue in all models, since questions remain about where and when to start the model run, and how the different input parameters should be tuned to match unknown boundary conditions. Our approach is meant only as a first analytical study of the question whether or not strain heating is important in the heat budget of these glaciers. The simplicity of the model also prevents us from simulating the longitudinal stress effects that influence the ice-speed distribution (e.g. the downslope acceleration/retardation of BSB flow).

The steep slopes of the glaciers are the main reason why strain heating is so effective in these examples. The average driving stress on the glaciers is $0.4 \mathrm{MPa}$, an effect of the ice descending $>1 \mathrm{~km}$ in altitude at an escarpment that separates the high plateau Amundsenisen from the lower plateau Ritscherflya. The lengths of the steep slopes are $10 \mathrm{~km}$, and the model shows that with stresses of $0.4 \mathrm{MPa}$ the basal ice can heat up to melting conditions in $\sim 10^{1}-10^{2}$ years. Put another way, the ice gains potential energy as it is forced down the escarpment by gravitational acceleration.

From these experiments, we find that large stresses exerted on ice bodies in Heimefrontfjella for a relatively short time and over restricted distances are large enough to warm the ice body to the point that the strain heat feedback will drive the ice to basal melting temperatures. Realistic amounts of vertical advection are insufficient to counteract this heating during this short time period.

The findings here can be applied more widely to improve understanding of the initiation of fast glacier flow. For the Heimefrontfjella glaciers, we find that steep slopes formed by bedrock steps with horizontal spacing of $\sim 10^{3}-10^{4} \mathrm{~m}$ may be sufficient to warm basal ice to pressure-melting conditions. This suggests that small-scale undulations may be important in the heat budget of ice masses, and that relatively small-scale steps in bedrock topography encourage the initiation of fast glacial flow. Furthermore, this shows that cryospheric models should use the smallest possible grids, especially in areas with large undulations in bedrock topography, in order to account fully for strain heating.

Finally, one may wonder if strain heating really is as simple as described in Equation (2). It is probably not exactly like this relation at the crystal size scale. Partial melting and recrystallization produces a flow of water between crystals that locally redistributes energy. At the larger scale, this should be averaged out if we have cold ice and no loss of water. An exception to this may exist if there is a case in which a recrystallized crystal lattice stores more energy in its new structure than the former lattice, as in change of fabric, or if the reverse situation exists. Detailed measurements of strain heating in granites have, however, shown that the measured heat production compares relatively well with theory (Blanpied and others, 1998), which supports the contention that Equation (2) is essentially correct in this case.

\section{ACKNOWLEDGEMENTS}

I. M. Whillans, J. F. Bolzan, R. S.W. van de Wal and C. J. van der Veen are thanked for stimulating and helpful discussions on issues of strain heating. Comments, discussions and reviews of different versions of the manuscript by C. Talbot, A.J. Payne, R. C. A. Hindmarsh, R. G. Bingham, N.W. Young and an anonymous reviewer are greatly appreciated. We thank P. Holmlund and J.-O. Näslund for help with the icedepth data. The Swedish Natural Science Research Council (NFR) is credited for funding post-doctoral research at Byrd Polar Research Center, The Ohio State University. We are also indebted to the Alfred Wegener Institute and Svenska Polarforskningssekreteriatet for logistical support.

\section{REFERENGES}

Anandakrishnan, S., R. B. Alley, R.W. Jacobel and H. Conway. 2001. The flow regime of Ice Stream C and hypotheses concerning its recent stagnation. In Alley, R. B. and R. A. Bindschadler, eds. The West Antarctic ice sheet: behavior and environment. Washington, DC, American Geophysical Union, 283-294. (Antarctic Research Series 77.)

Blanpied, M. L., T. E. Tullis and J. D. Weeks. 1998. Effects of slip, slip rate, and shear heating on friction of granite. F. Geophys. Res., 103(B1), 489-511.

Budd, W. 1969. The dynamics of ice masses. ANARE Sci. Rep., Ser. A (IV). Glaciol. 108.

Clarke, G. K. C., U. Nitsan and W. S. B. Paterson. 1977. Strain heating and creep instability in glaciers and ice sheets. Rev. Geophys. Space Phys., 15(2), 235-247.

Echelmeyer, K. A., W. D. Harrison, C. Larsen and J. E. Mitchell. 1994. The role of the margins in the dynamics of an active ice stream. F. Glaciol., 40(136), 527-538.

Fowler, A. C., T. Murray and F. S. L. Ng. 2001. Thermally controlled glacier surging. f. Glaciol., 47(159), 527-538.

Funk, M., K. Echelmeyer and A. Iken. 1994. Mechanisms of fast flow in Jakobshavns Isbræ, West Greenland: Part II. Modeling of englacial temperatures. 7. Glaciol., 40 (136), 569-585.

Hanson, B. 1995. A fully three-dimensional finite-element model applied to velocities on Storglaciären, Sweden. F. Glaciol., 41(137), 91-102. 
Hindmarsh, R. C. A. 2001. Influence of channeling on heating in ice-sheet flows. Geophys. Res. Lett., 28(19), 3681-3684.

Hindmarsh, R. C. A., G. S. Boulton and K. Hutter. 1989. Modes of operation of thermo-mechanically coupled ice sheets. Ann. Glaciol., 12, 57-69.

Hooke, R. LeB. 1981. Flow law for polycrystalline ice in glaciers: comparison of theoretical predictions, laboratory data, and field measurements. Rev. Geophys. Space Phys., 19(4), 664-672.

Humphrey, N. F. and C. F. Raymond. 1994. Hydrology, erosion and sediment production in a surging glacier: Variegated Glacier, Alaska, 1982-83. J. Glaciol., 40(136), 539-552.

Isaksson, E. and W. Karlén. 1994. Spatial and temporal patterns in snow accumulation, western Dronning Maud Land, Antarctica. 7. Glaciol., 40(135), 399-409.

Kamb, B. 1987. Glacier surge mechanism based on linked cavity configuration of the basal water conduit system. 7. Geophys. Res., 92(B9), 9083-9100.

Kamb, B. 2001. Basal zone of the West Antarctic ice streams and its role in lubrication of their rapid motion. In Alley, R. B. and R. A. Bindschadler, eds. The West Antarctic ice sheet: behavior and environment. Washington, DC, American Geophysical Union, 157-199. (Antarctic Research Series 77.)

Näslund, J.-O. 1997. Subglacial preservation of valley morphology at Amundsenisen, western Dronning Maud Land, Antarctica. Earth Surf. Processes Landforms, 22(5), 441-455.

Näslund, J.-O., V. Pohjola and A. Stroeven. 1991. Glaciological surveys in Vestfjella and Heimefrontfjella, Dronning Maud Land, Antarctica, 1989/90. Stockholms Univ. Naturgeogr. Inst. Forskningsrapp. 83, 1-71.

Näslund, J.-O., J. L. Fastook and P. Holmlund. 2000. Numerical modelling of the ice sheet in western Dronning Maud Land, East Antarctica: impacts of present, past and future climates. F. Glaciol., 46(152), 54-66. (Erratum: 46(153), p. 353-354)

Nye, J. F. 1965. The flow of a glacier in a channel of rectangular, elliptic or parabolic cross-section. 7. Glaciol., 5 (41), 661-690.

Paterson, W. S. B. 1994. The physics of glaciers. Thirdedition. Oxford, etc., Elsevier.
Payne, A. J. 1999. A thermomechanical model of ice flow in West Antarctica. Climate Dyn., 15(2), 115-125.

Payne, A. J. and P.W. Dongelmans. 1997. Self-organization in the thermomechanical flow of ice sheets. 7. Geophys. Res., 102(B6), 12,219-12,233.

Pohjola, V. A. 1993. Ice dynamical studies on Storglaciären. (Ph.D. thesis, Uppsala University.

Pohjola, V. A. and A. P. Stroeven. 1991. An ice dynamical investigation of an ice-stream at Heimefrontfjella, Dronning Maud Land. Ber. Polarforsch. 86, 123-126.

Raymond, C. F., K. A. Echelmeyer, I. M. Whillans and C. S. M. Doake. 2001. Ice stream shear margins. In Alley, R. B. and R. A. Bindschadler, eds. The West Antarctic ice sheet: behavior and environment. Washington, DC, American Geophysical Union, 137-155. (Antarctic Research Series 77.)

Richardson, G., E. Aarholt, S.-E. Hamran, P. Holmlund and E. Isaksson. 1997. Spatial distribution of snow in western Dronning Maud Land, East Antarctica, mapped by a ground-based snow radar. 7. Geophys. Res., 102(B9), 20,343-20,353

Richardson-Näslund, C. 2001. Spatial distribution of snow in Antarctica and other glacier studies using ground-penetrating radar. (Ph.D. thesis, Stockholm University.)

Robin, G. de Q. 1955. Ice movement and temperature distribution in glaciers and ice sheets. 7. Glaciol., 2(18), 523-532.

Saari, M. R., D. A. Yuen and G. Schubert. 1987. Climatic warming and basal melting of large ice sheets: possible implications for East Antarctica. Geophys. Res. Lett., 14(1),33-36.

Truffer, M., W. D. Harrison and K. A. Echelmeyer. 2000. Glacier motion dominated by processes deep in underlying till. F. Glaciol., 46(153), 213-221.

Verbitsky, M. and B. Saltzman. 1997. Modeling the Antarctic ice sheet. Ann. Glaciol., 25, 259-268.

Yuen, D. A., M. R. Saari and G. Schubert. 1986. Explosive growth of shearheating instabilities in the down-slope creep of ice sheets. F. Glaciol., 32(112), 314-320. 